\title{
The relationship of the skeletal muscle index and nutritional status in frail older hospital patients
}

\author{
A. Slee ${ }^{1}$, D. Birch ${ }^{2}$ and D. Stokoe ${ }^{3}$ \\ ${ }^{1}$ University of Lincoln, Lincoln, LN6 7TS, ${ }^{2}$ Lincoln Hospital, Lincoln, LN2 5QY and ${ }^{3}$ St Barnabas Hospice, Lincoln, \\ LN2 IRE
}

Skeletal muscle mass (SMM) has a dual functional role in illness and disease acting as a dynamic repository of amino acids which may be utilised to support the acute phase response ${ }^{1}$. This nutritional role of SMM may be important in frail older people who suffer from acute and chronic illness and are admitted to hospital. Specific guidelines have been developed for the assessment of sarcopenia/low SMM in older people ${ }^{2}$. We previously showed that frail older hospital patients may be under-categorised for malnutrition risk using the current UK routine screening tool (MUST) $)^{3}$.

Patient participants $\left(\mathrm{n}=69\right.$ (44 males, 25 females), age: $82 \pm 7 \cdot 5 \mathrm{y}(62-96)$, BMI: $\left.26 \cdot 0 \pm 5 \cdot 4 \mathrm{~kg} / \mathrm{m}^{2}(16 \cdot 6-45 \cdot 1)\right)$ were recruited from two hospital wards specialising in care of frail older patients in Lincoln. Full ethical approval was obtained from NHS East Midlands Research Ethics Committee prior to study commencement, ethical guidelines followed and informed consent sought from all patients. Bioelectrical impedance assessment (BIA) of SMM was determined using a Maltron ${ }^{\circledR}$ 916S BIA device at 50 khz frequency. SMM was converted into skeletal muscle index values (SMI, $\mathrm{kg} / \mathrm{m} 2)$ and compared and correlated against BMI and mini nutritional assessment short-form $\left(\mathrm{MNA}_{\mathrm{SF}}{ }^{\circledR}\right)$ scores. SMI reference cut-points were utilised to determine prevalence of sarcopenia/low $\mathrm{SMI}^{2}$.
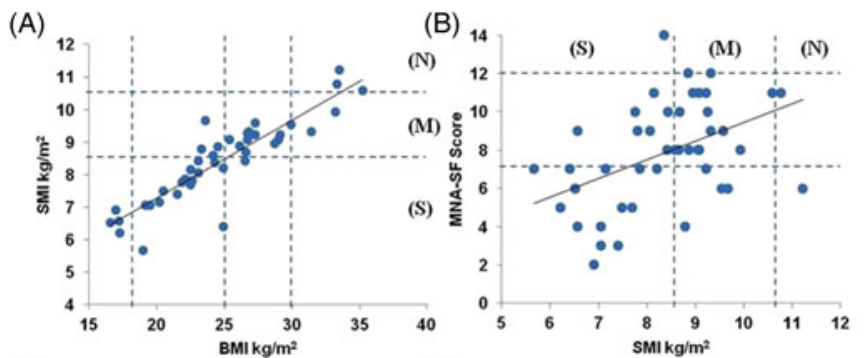

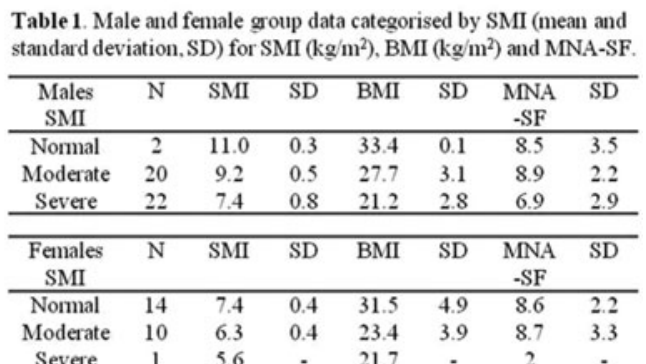
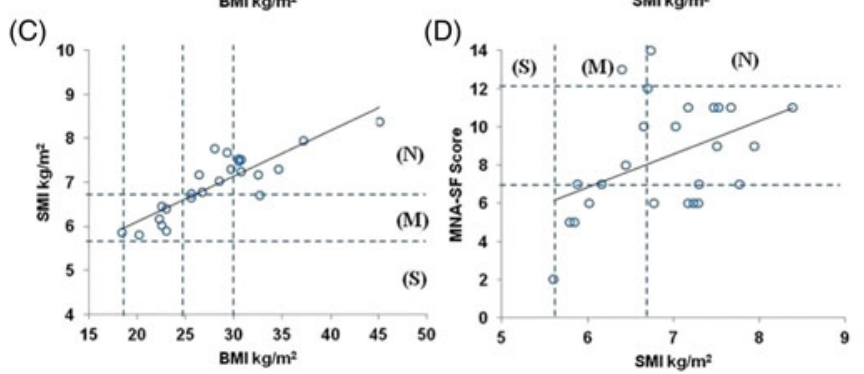

\begin{tabular}{lllllllll} 
Severe & 1 & 5.6 & - & 21.7 & - & 2 & - \\
\hline
\end{tabular}

-Sarcopenia/SMI categories': 'severe' (S) in men is $\leq 8.50$ $\mathrm{kg} / \mathrm{m}^{2}$ and in women $\leq 5.75 \mathrm{~kg} / \mathrm{m}^{2}$; 'moderate' $(M)$ in men is $8.51-10.75 \mathrm{~kg} / \mathrm{m}^{2}$ and in women $5.76-6.75 \mathrm{~kg} / \mathrm{m}^{2}$; and 'normal' $(\mathrm{N})$ is $\geq 10.76 \mathrm{~kg} / \mathrm{m}^{2}$ for men and women $\geq 6.76$ $\mathrm{kg} / \mathrm{m}^{2}$

•BMI classifications by WHO: 'underweight' $\left(<18.5 \mathrm{~kg} / \mathrm{m}^{2}\right)$, 'normal weight' $\left(18.5 \cdot 24.9 \mathrm{~kg} / \mathrm{m}^{2}\right)$, 'over-weight' $(25.0-29.9$ $\left.\mathrm{kg} / \mathrm{m}^{2}\right)$ and 'obese' $\left(\geq 30 \mathrm{~kg} / \mathrm{m}^{2}\right)$

-MNA-SF' screening score categoriest: 'malnourished' ( 0 -

7), 'at risk' (8-11) and 'normal' (12-14)

Figure 1. Male (closed circles) and female (open circles) comparison of SMI with BMI (A + C) and MNA-SF (B + D). Cut-points for SMI, BMI and MNA-SF categories are shown.

Table 1 and Figure 1 shows that males had a particularly high prevalence of severe/low $(50 \%, \mathrm{n}=22)$ and moderate $(45 \%, \mathrm{n}=20)$ SMI and corresponding 'malnourished' and 'at risk' MNA-SF scores (6.9 \pm 2.9 and $8.9 \pm 2 \cdot 2$, respectively), despite being within normal and overweight BMI ranges $\left(21.2 \pm 2.8\right.$ and $27.7 \pm 3.1 \mathrm{~kg} / \mathrm{m}^{2}$, respectively). Females were mostly within normal $(56 \%, \mathrm{n}=14)$ and moderate $(40 \%, \mathrm{n}=10) \mathrm{SMI}$ and within 'at risk' MNA-SF scores $(8 \cdot 6 \pm 2.2$ and $8.7 \pm 3 \cdot 3$, respectively). Correlations for SMI and BMI were: Group $(\mathrm{r}=0.53 ; \mathrm{P}<0.0001)$, males $(\mathrm{r}=0.90, \mathrm{P}<0.0001)$, females $(\mathrm{r}=0.81, \mathrm{P}<0.0001)$; SMI and MNA-SF score (0-14): Group $(\mathrm{r}=0.32 ; \mathrm{P}=0.008)$, males $(\mathrm{r}=0.49, \mathrm{P}=0.001)$, female $(\mathrm{r}=0.33, \mathrm{P}=0.11)$.

Male patients may be suffering from the potential coexistence of sarcopenia, cachexia and malnutrition which is not being highlighted by conventional screening tools routinely used in the UK. This preliminary data may have important nutritional and clinical implications for care of frail older people and requires further study in larger cohorts of patients. We further recommend validation of the Maltron ${ }^{\circledR}$ BIA equation for SMM estimation with a gold standard technique to confirm BIA accuracy.

1. Wolfe RR. Am J Clin Nutr 2006;84:475-82.

2. Cruz-Jentoft AJ, Baeyens JP, Bauer JM, et al. Age Ageing 2010;39:412-423.

3. Slee A, Birch D and Stokoe D. Clin Nutr 2014; Article in Press DOI: 10.1016/j.clnu.2014.04.013.

4. Nestle Nutrition Institute, 2011:http://www.mna-elderly.com/geriatric_assessment.html. 